\title{
Parathyroid Hormone Replacement Therapy in Hypoparathyroidism: A Meta-Analysis
}

\author{
Authors \\ Affiliations \\ X.-x. Liu ${ }^{1}$, X.-y. Zhu ${ }^{2}$, G.-h. Mei ${ }^{3}$ \\ Department of Endocrinology, Huashan Hospital, Shanghai Medical College, Fudan University, Shanghai, China \\ Department of Neurology, Shanghai First People's Hospital, Shanghai Jiao Tong University, Shanghai, China \\ Department of Neurosurgery, Huashan Hospital, Shanghai Medical College, Fudan University, Shanghai, China
}

Key words

- parathyroid hormone 1-34

- calcitriol

- calcium

- bone mineral density received 16.09.2015

accepted 13.04.2016

\section{Bibliography}

Dol http://dx.doi.org/

10.1055/s-0042-106970

Horm Metab Res 2016;

48: 377-383

(c) Georg Thieme Verlag KG

Stuttgart · New York

ISSN 0018-5043

Correspondence

\section{G.-h. Mei}

No.12, Wulumuqi Road (Middle)

Shanghai 200040

China

Tel.: + 86/21/38719999 5900

Fax: + 86/21/5030 9926

meighai@126.com

\section{Abstract}

This study investigated the effect of human parathyroid hormone replacement therapy on specific disease-related outcomes in patients with hypoparathyroidism. Medline, Cochrane, EMBASE, and Google Scholar databases were searched until January 13, 2015 for randomized trials using the following search terms: hypoparathyroidism, parathyroid hormone/PTH, and hormone replacement therapy. Five randomized controlled trials $(n=245)$ that investigated effect of either PTH (1-34) (3 trials) or PTH (1-84) (2 trials) on serum calcium, phosphate, 1, 25-dihydroxyvitamin D, 25-dihydroxyvitamin D levels, and urine level of calcium were included in the meta-analysis. Both PTH (1-34) and PTH (1-84) therapies were not associated with change in serum calcium level compared with calcitriol/placebo. The level of 24-h urine calcium excretion had a significant decrease

\section{Introduction}

\section{$\nabla$}

Hypoparathyroidism is a rare disorder associated with low or absent production of parathyroid hormone (PTH). PTH deficiency results in abnormal mineral homeostasis and is characterized by hypocalcemia, hyperphosphatemia, and hypomagnesemia [1]. In the kidneys, PTH promotes calcium reabsorption, phosphate excretion, and conversion of $25(\mathrm{OH}) \mathrm{D}$ by $1 \alpha$-hydroxylase to $1,25(\mathrm{OH})_{2} \mathrm{D}$. In the intestines, $1,25(\mathrm{OH})_{2} \mathrm{D}$ enhances the absorption of calcium and, to a lesser degree, phosphate [1]. PTH deficiency disrupts normal mineral homeostasis by lowering intestinal and renal calcium absorption due to reduced renal conversion of 25-hydroxyvitamin D to active 1,25-dihydroxyvitamin D [2-4]. Lack of PTH also decreases bone turnover. A reduction or absence of circulating PTH leads initially to a decrease in bone resorption and then to a coupled reduction in bone formation [2-5]. In adults, the cause of hypoparathyroidism in PTH (1-34)-treated group compared placebo/ calcitriol (control) group ( $\mathrm{p} \leq 0.012)$. PTH $(1-34)$ did not change serum phosphate $(\mathrm{p}=0.053)$. PTH (1-84) did not change level of 24-h urine calcium excretion compared with control $(p \geq 0.214)$ but it did decrease the levels of serum phosphorous $(p=0.000)$. Both PTH-replacement therapies were not associated with change in serum 1,25-dihydroxyvitamin $\mathrm{D}$ level compared with control $(p \geq 0.606)$, but were associated with a significant decrease in serum 25-dihydroxyvitamin D levels $(\mathrm{p} \leq 0.04)$. In conclusion, although the number of randomized trial is limited, our meta-analysis suggests that PTH (1-34) replacement therapy may maintain the serum calcium levels in the normal range by reducing the levels of urine calcium excretion, and both replacement therapies may maintain 1,25-dihydroxyvitamin D serum levels by reducing serum level of 25-dihydroxyvitamin D.

is typically the result of a complication of neck surgery or radiation $[2,3,6]$. Hypoparathyroidism can also result from a number of genetic or autoimmune disorders including familial isolated hypoparathyroidism, DiGeorge syndrome, autoimmune polyendocrine insufficiency type 1 with immune-mediated destruction of the parathyroid glands, and autosomal dominant hypocalcemia resulting from activating mutations in the calcium-sensing receptor [5,7-10].

The current conventional treatment for hypoparathyroidism is large doses of oral calcium and active vitamin $\mathrm{D}$ metabolites or analogues to relieve the symptoms caused by hypocalcemia $[11,12]$. However, this approach is not always successful in controlling the disease and precisely controlling serum calcium levels $[1,13,14]$. Short- and long-term complications include large swings in serum calcium levels (hypo or hypercalcemia) and risk of calcification of the brain, kidney, and other tissues $[1,15]$. 
Several studies have evaluated the use of hormone replacement therapy in treating hypoparathyroidism using either full-length hormone PTH (1-84) or the biologically active fragment PTH (1-34). Both PTH (1-34) and PTH (1-84) are commercially produced by recombinant DNA technology and are on the market as Forte ${ }^{\circledR}$ and Natpara ${ }^{\circledR}$, respectively. All of the clinical studies of PTH (1-34) included in this analysis, however, were performed at the NIH where they used synthetic human PTH (1-34) formulated by the NIH pharmacy [6]. Overall, prior studies investigating the use of PTH-replacement therapy for hypoparathyroidism found that PTH-replacement therapy can maintain normal serum calcium and phosphate levels or reduce the levels of concurrent treatment with calcium and active vitamin D analogues by improving PTH-dependent renal calcium reabsorption or correct diminished bone turnover $[1,5,6]$.

In January 2015, PTH (1-84) was approved in the United States by the Federal Drug Administration (FDA) as adjunct therapy to calcium and vitamin $\mathrm{D}$ therapy for the control of hypocalcemia in patients with hypoparathyroidism [1]. Therefore, PTH (1-84) $\left(\right.$ Natpara $\left.^{\circledR}\right)$ is recently available as an adjunct to conventional therapy for patients who are refractory to calcium and calcitriol alone [1]. Recombinant PTH (1-34) $\left(\right.$ Forteo $\left.^{\circledR}\right)$ was approved in 2002 for treatment of severe osteoporosis in adults and, over the past decade, has been used extensively both in Europe and in the US as an off-label replacement therapy for hypoparathyroidism [16]. Toxicology studies in rats found both PTH (1-34) and PTH (1-84) led to dose dependent osteosarcomas in rats [17]. Consequently, both drugs are contraindicated for use in children and the FDA issued a black box warning against use in children [6].

To date, most of the previous studies have been small, which limits the interpretation of some of the findings $[6,18]$. In addition, the results for renal calcium excretion and phosphate levels have been variable [6]. This study investigated the effect of human parathyroid hormone replacement therapy on specific diseaserelated outcomes, including serum and urine calcium levels, serum phosphate levels, and levels of 25-hydroxyvitamin D and 1,25-dihydroxyvitamin $\mathrm{D}$ in patients with hypoparathyroidism.

\section{Materials and Methods}

$\nabla$

\section{Search strategy}

This meta-analysis was performed in accordance with PRISMA guidelines. Medline, Cochrane, EMBASE, and Google Scholar databases were searched until January 13, 2015 using the following search terms: hypoparathyroidism, parathyroid hormone/PTH, hormone replacement therapy, vitamin D, calcitriol, and calcium. Randomized controlled trials (RCTs) and $2 \mathrm{arm}$, nonrandomized prospective studies, which investigated treatment in patients who had chronic hypoparathyroidism $\geq 18$ months were included. All included studies had to quantitatively report the outcomes of interest. Retrospective studies, cohort studies; letters, comments, editorials, case report; proceeding, and personal communications were excluded. The lists of potential studies were hand searched by 2 independent reviewers, and if necessary, a third reviewer was consulted to resolve any discrepancies regarding study eligibility.

\section{Data extraction}

The following information/data was extracted from studies that met the inclusion criteria: the name of the first author, year of publication, study design, number of participants in each group, participants' age and gender, intervention, and outcomes (e.g., serum calcium levels, 24-h urine calcium level, serum phosphate level, and serum 25-dihydroxyvitamin D and 1,25-dihydroxyvitamin D levels).

\section{Quality assessment}

The quality of each included study was assessed using the Cochrane Collaboration's tool for assessing risk to assess the included studies [19]. Two reviewers assessed the quality of the studies and a third was consulted for solving any discrepancies.

\section{Statistical analysis}

The primary outcome was serum calcium levels and 24-h urine calcium levels. Secondary outcomes were levels of serum phosphorous, 1,25-dihydroxyvitamin D, and 25-hydroxyvitamin D.

Standardized difference in means (or so called standard mean difference) was used as the index of effect size that represented the effect of PTH-replacement therapy in the treatment of hypoparathyroidism. Heterogeneity was assessed by Cochran's $Q$ statistic and $I^{2}$. Cochran's $Q$ statistic was defined as the weighted sum of the squared deviations of the estimates of all studies and $\mathrm{I}^{2}$ indicated the percentage of the observed betweenstudy variability caused by heterogeneity. Either the Q statistic with $\mathrm{p}<0.1$ or $\mathrm{I}^{2}>50 \%$ was considered indicative of heterogeneity. If heterogeneity existed, standardized difference in means of selected studies was pooled under random effect model using the DerSimonian-Laird approach. Otherwise, the fixed-effects model (Mantel-Haenszel approach) was used. Sensitivity analysis was performed by the leave-one-out approach. A2-sided p-value $<0.05$ was considered statistically significant. Publication bias was not evaluated as at least 5 studies are necessary for this analysis [20]. All statistical analyses were performed using Comprehensive Meta-Analysis, version 2.0 (Biostat, Englewood, NJ, USA).

\section{Results}

$\nabla$

The initial search identified 181 potential studies of which 161 were excluded for not being relevant ( $\bullet$ Fig. 1). After a complete full-text review of the remaining 20 studies, 15 were eliminated

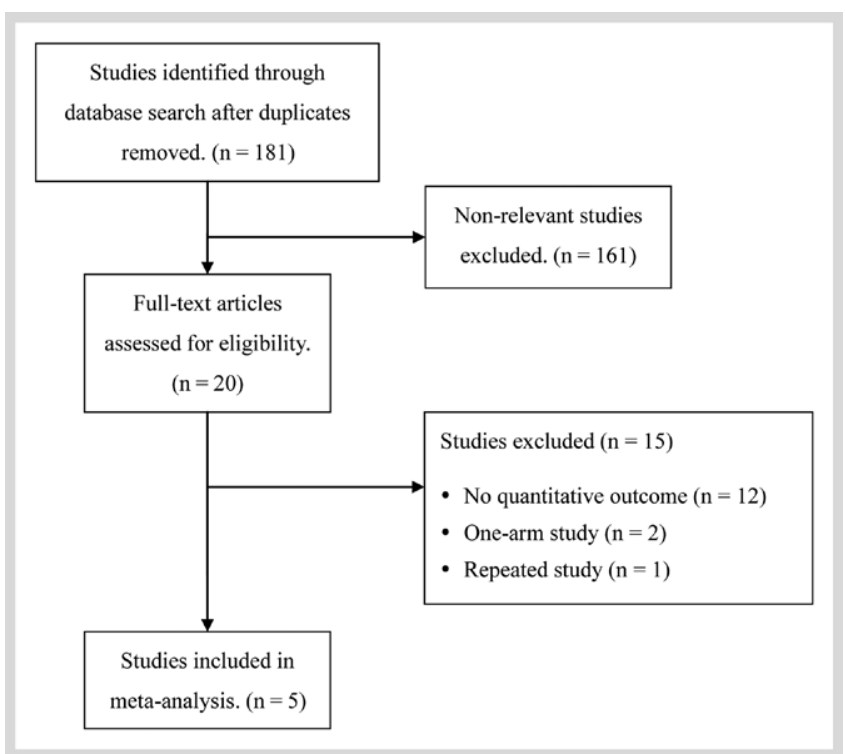

Fig. 1 Flow chart for study selection. 
Table 1 Summary of basic characteristics of selected studies for meta-analysis.

\begin{tabular}{|c|c|c|c|c|c|c|c|c|}
\hline Study & Study design & $\begin{array}{l}\text { Interven- } \\
\text { tions }\end{array}$ & $\begin{array}{l}\text { Supplement treat- } \\
\text { ment }\end{array}$ & $\begin{array}{l}\text { Number of } \\
\text { patients }\end{array}$ & $\begin{array}{l}\text { Age } \\
\text { (years) }^{a}\end{array}$ & $\begin{array}{l}\text { Male } \\
(\%)\end{array}$ & $\begin{array}{l}\text { Duration of dis- } \\
\text { ease }^{\text {a }} \text { (years) }\end{array}$ & $\begin{array}{l}\text { Follow-up } \\
\text { time }\end{array}$ \\
\hline \multirow{2}{*}{$\begin{array}{l}\text { Sikjaer et al. } \\
2011[14]\end{array}$} & \multirow[t]{2}{*}{$\mathrm{RCT}$} & PTH (1-84) & \multirow{2}{*}{$\begin{array}{l}\text { Oral calcium, vita- } \\
\text { min D analogues }{ }^{\dagger}\end{array}$} & 32 & $53(38-78)^{b}$ & 19 & $9.5(2-33)^{b}$ & \multirow[t]{2}{*}{24 weeks } \\
\hline & & Placebo & & 30 & $51(31-73)^{b}$ & 10 & $8(1-37)^{b}$ & \\
\hline \multirow{2}{*}{$\begin{array}{l}\text { Winer et al. } \\
2010[16]\end{array}$} & \multirow[t]{2}{*}{$\mathrm{RCT}$} & PTH (1-34) & \multirow{2}{*}{$\begin{array}{l}\text { Combined calcium } \\
\text { and cholecalciferol }\end{array}$} & 7 & $10.2(2.3)$ & 60 & \multirow[t]{2}{*}{$\mathrm{n} / \mathrm{a}^{*}$} & \multirow[t]{2}{*}{3 years } \\
\hline & & Calcitriol & & 5 & $8.8(2.9)$ & 71 & & \\
\hline \multirow{2}{*}{$\begin{array}{l}\text { Winer et al. } \\
2003 \text { [18] }\end{array}$} & \multirow[t]{2}{*}{$\mathrm{RCT}$} & PTH (1-34) & \multirow[t]{2}{*}{ Calcium } & 14 & $38(18-70)$ & 29 & $12(1-35)$ & \multirow[t]{2}{*}{3 years } \\
\hline & & Calcitriol & & 13 & $43(18-64)$ & 46 & $18(1-36)$ & \\
\hline \multirow{2}{*}{$\begin{array}{l}\text { Winer et al. } \\
1996 \text { [21] }\end{array}$} & \multirow{2}{*}{$\begin{array}{l}\text { Randomized } \\
\text { Crossover Trial }\end{array}$} & PTH (1-34) & none & 10 & $45.5(14.5)$ & 60 & \multirow[t]{2}{*}{$17(2,41)^{b}$} & \multirow[t]{2}{*}{10 weeks } \\
\hline & & Calcitriol & Calcium carbonate & & & & & \\
\hline \multirow{2}{*}{$\begin{array}{l}\text { Mannstadt et al. } \\
2013 \text { [13] }\end{array}$} & \multirow[t]{2}{*}{$\mathrm{RCT}$} & rhPTH (1-84) & \multirow{2}{*}{$\begin{array}{l}\text { Oral calcium, vita- } \\
\text { min D analogue } \ddagger\end{array}$} & 90 & $47.0(12.2)$ & 23 & $14.1(11.14)$ & \multirow[t]{2}{*}{24 weeks } \\
\hline & & Placebo & & 44 & $48.5(13.7)$ & 18 & $11.0(7.98)$ & \\
\hline \multicolumn{9}{|c|}{ a Data were shown by mean (SD) } \\
\hline \multicolumn{9}{|c|}{ b Shown by median (range) } \\
\hline
\end{tabular}

for not reporting the outcomes of interest quantitatively $(n=12)$, being single-arm studies $(\mathrm{n}=2)$, and being a repeated study of an included RCT $(\mathrm{n}=1)$.

Five studies were included finally in the meta-analysis $[13,14,16,19,20]$. Winer et al. [18] reported the findings from a 3-year long-term randomized, parallel group, open-label study, of which a number of the participants (21/27) were recruited from previous RCTs from the same research group [21,22]. In the study of Winer et al. (2003) [18], only 6 subjects had not been exposed to PTH therapy.

Four studies were randomized controlled studies $[13,14,16,18]$ and one study was a randomized crossover trial [20] ( $\triangle$ Table 1 ). Two of the 4 studies investigated the effect of PTH (1-84) compared with placebo $[13,14]$, and the other 3 studies evaluated the effect of PTH (1-34) compared with calcitriol (1,25-dihydroxyvitamin D) $[16,18,21]$. All subjects also received calcium, vitamin $\mathrm{D}$, or $\alpha$-calcidol/calcitriol/ergocalciferol as dietary supplement ( $\diamond$ Table 1 ). Together the 5 studies included 245 subjects. Across the studies, the mean duration of disease ranged from 8-17 years, and the mean follow-up time was from 10 weeks to 3 years. The mean age of participants ranged from 8.8 to 53 years of age. One long-term randomized, parallel group, open-label study was specifically designed for pediatric patients (age 5-14 years) [16]. The studies of Winer et al. (2010) [16] and Winer et al. (1996) [21] consisted mostly of males (60-71\%), while those of Sikjaer et al. (2011) [14], Winer et al. (2003) [18], and Mannstadt et al. (2013) [13] primarily recruited females (71-90\%).

\section{Meta-analysis}

Analysis of the data for serum calcium level indicated the presence of heterogeneity across studies; therefore, a random effects model was used to generate pooled estimates $[\mathrm{Q}=5.03, \mathrm{p}=0.081$, $\mathrm{I}^{2}=60.2 \%$ for PTH $(1-34) ; \mathrm{Q}=3.35, \mathrm{p}=0.067, \mathrm{I}^{2}=70.1 \%$ for PTH (1-84)] ( $\odot$ Fig. 2a). Analysis of the data for urine calcium level indicated no heterogeneity across studies; therefore, a fixedeffects model was used to generate pooled estimates $[Q=0.92$, $\mathrm{p}=0.633, \mathrm{I}^{2}=0 \%$ for PTH $(1-34) ; \mathrm{Q}=0, \mathrm{p}=1.00, \mathrm{I}^{2}=0 \%$ for PTH (1-84)] ( Fig. 2b). Analysis of the data for serum phosphate level indicated no heterogeneity across studies; therefore, a fixed-effects model was used to generate pooled estimates $\left(\mathrm{Q}=0.54, \mathrm{p}=0.764, \mathrm{I}^{2}=0 \%\right.$ for $\mathrm{PTH}(1-34) ; \mathrm{Q}=44, \mathrm{p}=0.506, \mathrm{I}^{2}=0 \%$ for PTH (1-84)) (॰ Fig. 2c).
The pooled standardized difference in mean serum calcium level between PTH-treated and calcitriol/placebo-treated subjects was $0.349(95 \% \mathrm{CI}=-0.383-1.082, \mathrm{p}=0.350)$ for PTH $(1-34)$ and $0.414(95 \% \mathrm{CI}=-0.238-1.066, \mathrm{p}=0.214)$ for PTH $(1-84)$, indicating no significant increase in serum calcium level in the PTHtreatment groups relative to the calcitriol/placebo (control) group ( $\bullet$ Fig. 2a). In contrast, the 24-h urine calcium levels significantly decrease in the PTH (1-34)-treated group compared with the control group (standardized difference in means $=-0.696,95 \% \mathrm{CI}=-1.225$ to $-0.167, \mathrm{p}=0.010$ ) ( $\odot$ Fig. 2 b) . No change in urine calcium level relative to control was observed in the PTH (1-84)-treatment group. PTH (1-34) therapy did not change serum phosphate levels compared with control $(\mathrm{p}=0.053)$, but PTH (1-84) treatment resulted in a significant decrease in phosphate levels compared with control (standardized difference in means $=-0.592,95 \% \mathrm{CI}=-0.890$ to -0.294 , $\mathrm{p}=0.000$ ) (॰ Fig. 2c).

Analysis of the data indicated heterogeneity among the studies for the serum levels of 1,25 -dihydroxyvitamin $D[Q=11.18$, $\mathrm{p}=0.001, \mathrm{I}^{2}=91.1 \%$ for PTH $(1-34) ; \mathrm{Q}=6.94, \mathrm{p}=0.008, \mathrm{I}^{2}=85.6 \%$ for PTH (1-84)] and in 25-dihydroxyvitamin D levels for PTH $(1-34)\left(\mathrm{Q}=4.35, \mathrm{p}=0.037, \mathrm{I}^{2}=77.0 \%\right)$; therefore, a random effects model was used to generate the pooled estimates ( $\bullet$ Fig. 3a, b). The subgroup of PTH (1-84) indicated no heterogeneity among the studies for 25-dihydroxyvitamin $\mathrm{D}$ level $(\mathrm{Q}=0.24, \mathrm{p}=0.623$, $\mathrm{I}^{2}=0 \%$; therefore, a fixed-effects model was used to generate the pooled estimates ( $\bullet$ Fig. $\mathbf{3 b}$ ).

The results showed that there was no difference in 1,25-dihydroxyvitamin D levels between PTH-replacement and calcitriol/ placebo treatment groups regardless of types of PTH agent used (PTH (1-34): pooled standardized difference in means $=1.060$, 95\% CI $=-0.428-2.547, \mathrm{p}=0.163$; PTH (1-84): pooled standardized difference in means $=0.326,95 \% \mathrm{CI}=-0.912-1.565, \mathrm{p}=0.606)$ ( $\odot$ Fig. 3a). However, both PTH (1-34) (standardized difference in means $=-0.954,95 \% \mathrm{CI}=-1.863$ to $-0.044, \mathrm{p}=0.040)$ and $\mathrm{PTH}$ (1-84) (standardized difference in means $=-0.639$, 95\% $\mathrm{CI}=-1.207$ to $-0.071, \mathrm{p}=0.028$ ) treatments were associated with a significant decrease in serum 25-dihydroxyvitamin D levels (๑ Fig. 3b).

Sensitivity analysis, in which each study was left out in turn, indicated that the study of Winer et al. (2003) [18] had a mild influence over the pooled estimates for serum calcium levels ( standardized difference in means $=0.493,95 \% \mathrm{CI}=0.003-0.983$, 


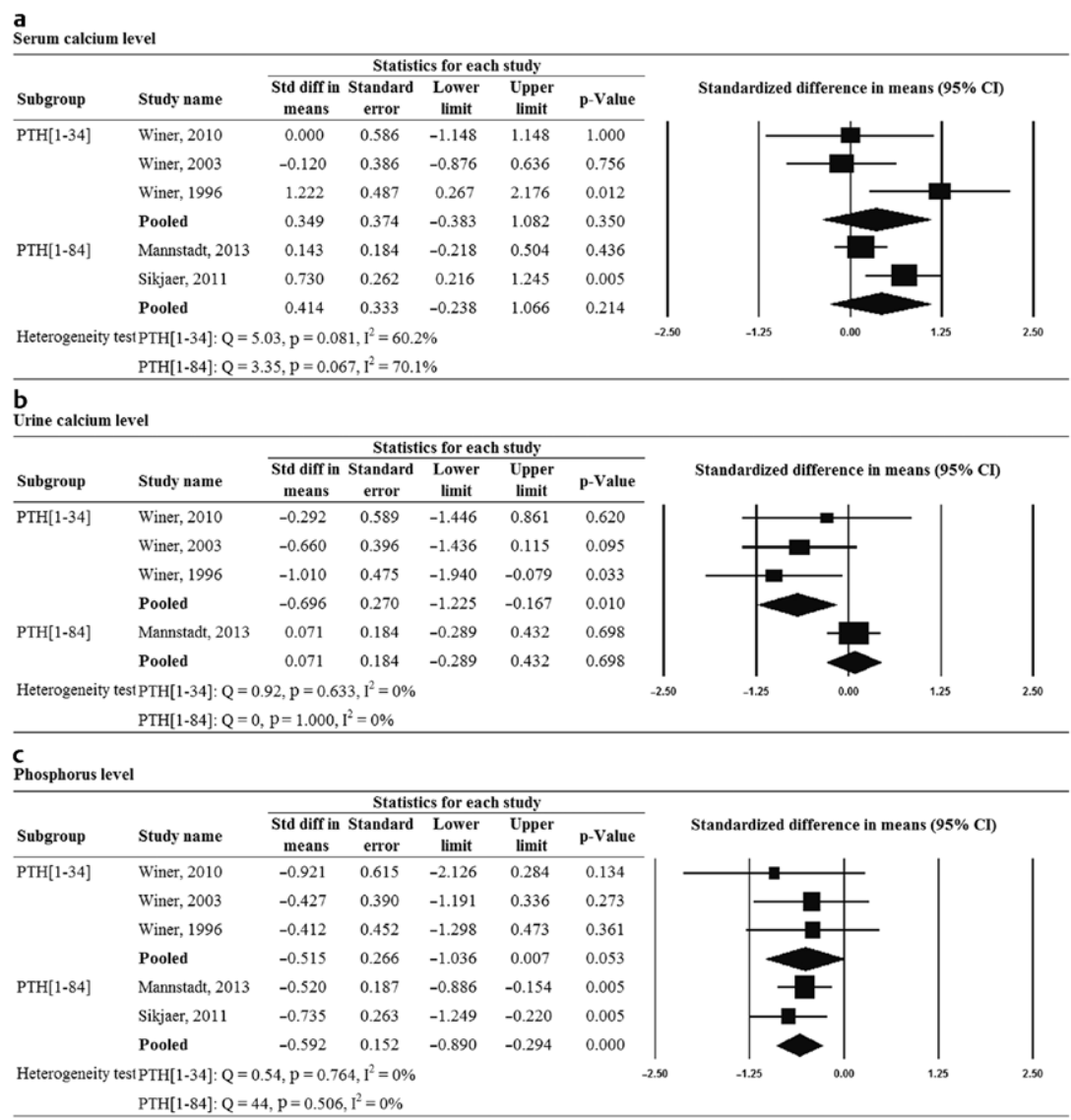

a

\begin{tabular}{|c|c|c|c|c|c|c|c|}
\hline \multirow[b]{2}{*}{ Subgroup } & \multirow{2}{*}{ Study name } & \multicolumn{5}{|c|}{$\begin{array}{c}\text { Statistics for each study } \\
\end{array}$} & \multirow[b]{2}{*}{ Standardized difference in means $(95 \% \mathrm{Cl})$} \\
\hline & & Std diff in & Standard & Lower & Upper & p-Value & \\
\hline \multirow[t]{3}{*}{ PTH[1-34] } & Winer, 2010 & 3.008 & 0.848 & 1.345 & 4.671 & 0.000 & \\
\hline & Winer, 1996 & -0.200 & 0.448 & -1.079 & 0.679 & 0.656 & \\
\hline & Pooled & 1.060 & 0.759 & -0.428 & 2.547 & 0.163 & \\
\hline \multirow[t]{3}{*}{ PTH[1-84] } & Mannstadt, 2013 & -0.087 & 0.184 & -0.448 & 0.273 & 0.635 & \\
\hline & Sikjaer, 2011 & 0.759 & 0.263 & 0.243 & 1.274 & 0.004 & \\
\hline & Pooled & 0.326 & 0.632 & -0.912 & 1.565 & 0.606 & \\
\hline \multicolumn{7}{|c|}{ Heterogeneity } & -2.00 \\
\hline
\end{tabular}

Heterogeneity test PTH $[1-34]$

b

PTH[1-84]: $\mathrm{Q}=6.94, \mathrm{p}=0.008, \mathrm{I}^{2}=85.6 \%$

Serum 25-hydroxyvitamin D leve

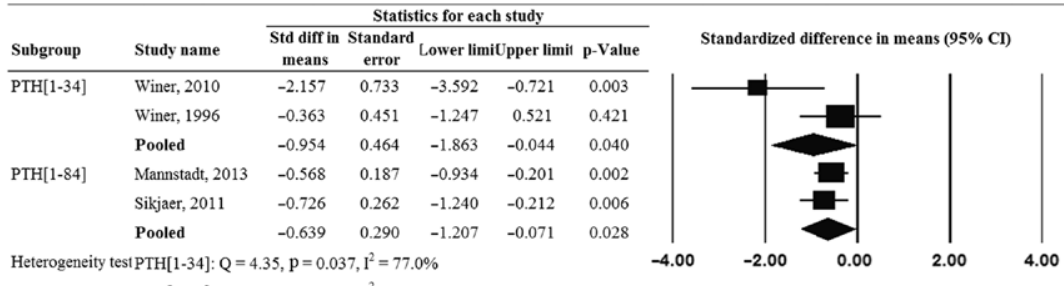

Fig. 2 Forest plots for treatment effect on a serum calcium levels, b 24-h urine calcium level, and $\mathbf{c}$ serum phosphate level in patients with hypoparathyroidism. $\mathrm{p}=0.049)$; pooled results became significant when Winer et al. (2003) [18] was removed ( $\odot$ Fig. 4a). In addition, the study of Mannstadt et al. (2013) [13] may have overly impacted the result of the 24-h urine calcium level (standardized difference in means $=-0.696,95 \% \mathrm{CI}=-1.225$ to $-0.167, \mathrm{p}=0.010$ ); pooled results became statistically significant when Mannstadt et al. (2013) [13] was removed (๑ Fig. 4b).

To assess whether the age of patients may have influenced our pooled results for the treatment of PTH (1-34) on both primary
Fig. 3 Forest plots for treatment effect on a 1,25-dihydroxyvitamin D and b 25-hydroxyvitamin $\mathrm{D}$ in patients with hypoparathyroidism. outcomes, subgroup analyses that evaluated the adult patient results were conducted ( $\bullet$ Fig. 5). Two studies with adult patients for each PTH (1-34) treatment were included in the analysis. The results showed that there was no association between serum calcium level and treatment of PTH (1-34) (standardized difference in means $=0.518$, 95\% CI $=-0.795-$ $1.831, \mathrm{p}=0.440)$. On the other hand, a significantly decrease in urine calcium level was found the PTH (1-34)-treated group compared with the control group (standardized difference in means $=-0.803,95 \% \mathrm{CI}=-1.399$ to $-0.208, \mathrm{p}=0.008)$ (๑ Fig. 5). 


\begin{tabular}{|c|c|c|c|c|c|c|}
\hline \multirow[b]{2}{*}{ Study name } & \multicolumn{5}{|c|}{$\begin{array}{l}\text { Statistics with study removed } \\
\end{array}$} & \multirow[b]{2}{*}{ Standardized difference in means $(95 \% \mathrm{CI})$} \\
\hline & $\begin{array}{l}\text { Std diff } \\
\text { in means }\end{array}$ & $\begin{array}{l}\text { Standard } \\
\text { error }\end{array}$ & $\begin{array}{c}\text { Lower } \\
\text { limit }\end{array}$ & $\begin{array}{c}\text { Upper } \\
\text { limit }\end{array}$ & p-Value & \\
\hline Mannstadt, 2013 & 0.484 & 0.295 & -0.095 & 1.062 & 0.101 & \\
\hline Sikjaer, 2011 & 0.254 & 0.248 & -0.233 & 0.741 & 0.307 & \\
\hline Winer, 2010 & 0.430 & 0.249 & -0.058 & 0.919 & 0.084 & \\
\hline Winer, 2003 & 0.493 & 0.250 & 0.003 & 0.983 & 0.049 & \\
\hline Winer, 1996 & 0.259 & 0.193 & -0.120 & 0.637 & 0.180 & \\
\hline Pooled & 0.379 & 0.219 & -0.049 & 0.807 & 0.083 & $\underset{-1.25}{1}$ \\
\hline
\end{tabular}

b

Urine calcium level

\begin{tabular}{|c|c|c|c|c|c|c|}
\hline \multirow[b]{2}{*}{ Study name } & \multicolumn{5}{|c|}{ Statistics with study removed } & \multirow[b]{2}{*}{ Standardized difference in means $(95 \% \mathrm{CI})$} \\
\hline & $\begin{array}{l}\text { Std diff } \\
\text { in means }\end{array}$ & $\begin{array}{l}\text { Standard } \\
\text { error }\end{array}$ & $\begin{array}{c}\text { Lower } \\
\text { limit }\end{array}$ & $\begin{array}{c}\text { Upper } \\
\text { limit }\end{array}$ & p-Value & \\
\hline Mannstadt, 2013 & -0.696 & 0.270 & -1.225 & -0.167 & 0.010 & \\
\hline Winer, 2010 & -0.163 & 0.157 & -0.472 & 0.145 & 0.299 & \\
\hline Winer, 2003 & -0.087 & 0.165 & -0.410 & 0.236 & 0.597 & \\
\hline Winer, 1996 & -0.076 & 0.161 & -0.391 & 0.238 & 0.635 & \\
\hline \multirow[t]{2}{*}{ Pooled } & -0.172 & 0.152 & -0.470 & 0.126 & 0.258 & \\
\hline & & & & & & -1.25 \\
\hline
\end{tabular}

C

Phosphorus level

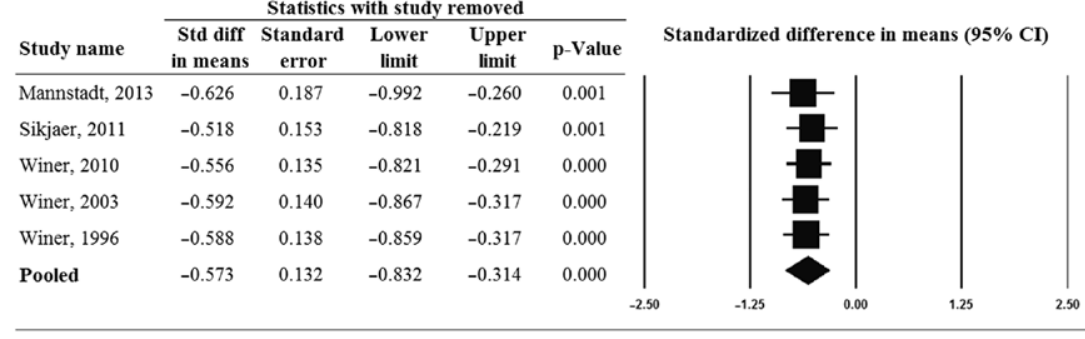

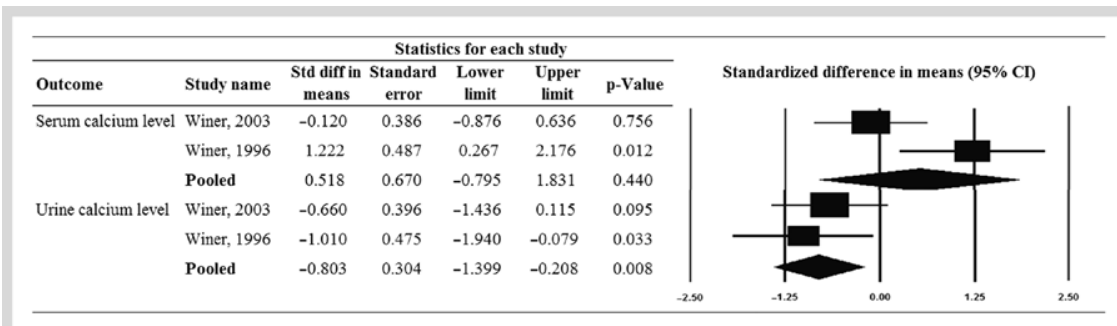

Fig. 4 Sensitivity-analysis for a serum calcium levels, b 24h-urine calcium level, and c serum phosphate level.

\section{Quality assessment}

Quality assessment indicated that all the studies were of good quality. All 4 of the studies were randomized controlled studies minimizing selection bias. There was low risk of attrition or reporting bias, and for the studies reported the necessary information, there was low risk of performance or detection bias. Three of the 5 studies had intention-to-treat analysis.

\section{Discussion}

The purpose of this study was to evaluate the efficacy of human PTH-replacement therapy in adults and children with hypoparathyroidism. This meta-analysis found PTH-replacement therapy, regardless if it was with PTH (1-34) or PTH (1-84), was not associated with a greater increase in levels of serum calcium compared with placebo/calcitriol control. The analysis also found that PTH (1-34) resulted in a significant decrease in urine calcium levels relative to placebo/calcitriol $(p=0.01)$, but there was no significant difference with regard to phosphorous com-
Fig. 5 Forest plot for treatment effect of PTH (1-34) on primary outcomes in studies recruiting adult participants only. 
this meta-analysis study is that by evaluating the pooled data for PTH (1-34) and PTH (1-84) treatments, it gives additional insight into the benefit and the activity of the different PTH therapies in treating hypoparathyroidism.

Analysis of the efficacy of PTH (1-34) and PTH (1-84) separately found that mean serum calcium was maintained within or slightly below normal range (nonsignificant difference) but urine calcium was significantly decreased after the PTH (1-34) treatment. PTH (1-34) did reduce the urine calcium level to the normal range $(1.25-6.25 \mathrm{mmol} / 24 \mathrm{~h})$. These findings may suggest that PTH (1-34) maintains the serum calcium level by increasing renal calcium reabsorption and decreasing urine calcium excretion.

In the RCTs included in this study, patients received oral calcium and vitamin D analogue(s) as supplement treatment. However, as above mentioned, short- and long-term complications indicate that large swings in serum calcium levels (hypo- or hypercalcemia) may occur after the treatment. Furthermore, studies with PTH (1-84) did not achieve this important goal of reducing urine calcium possibly because patients received large, fixed, single daily doses. Mean serum 1,25-dihydroxyvitamin D concentrations were maintained in the normal range but mean serum concentration of 25-hydroxyvitamin D decreased in both PTH (1-34) and PTH (1-84) groups. A decrease in serum level of 25-hydroxyvitamin D implied that PTH therapy maintained the serum level of 1,25-hydroxyvitamin $\mathrm{D}$ by improving conversion of $25(\mathrm{OH}) \mathrm{D}$ by $1 \alpha$-hydroxylase to $1,25(\mathrm{OH})_{2} \mathrm{D}$. In an RCT reported by Mannstadt et al. (2013) [13], 1,25-dihydroxyvitamin D concentrations patients treated with PTH (1-84) were maintained in the normal range despite reductions in oral calcium and active vitamin D [13].

Potential advantages of PTH-replacement therapy is that it may result in improved maintenance of serum calcium levels and reduce the need for treating with calcium and active vitamin $\mathrm{D}$ or vitamin D analogues [6]. PTH-replacement therapy may also lower urinary calcium, improve bone quality, reduce ectopic tissue calcification, and improved quality of life $[23,24]$. In addition, there is evidence that hypoparathyroidism is associated with elevated cholesterol levels, a risk factor for cardiovascular disease [25]. It is unclear if PTH-replacement therapy would affect cholesterol levels.

This meta-analysis suggests that PTH-replacement therapy can simultaneously maintain normal serum and urine calcium. Several prior studies found PTH-replacement therapy reduced the need for additional calcium or vitamin $\mathrm{D}$ and improved bone mineral density [14]. We did not analyze if the use of PTHreplacement therapy resulted in a reduction in the need for calcium supplementation or vitamin D or its analogues. We also did not evaluate the impact of PTH-replacement therapy on bone mineral density.

Currently, PTH is marketed for the treatment of osteoporosis and is only available at a fixed dose of $20 \mu \mathrm{g}$ (teriparatide; Forteo ${ }^{\circledR}$, Eli Lilly and Company, Indianapolis, IN, USA) [28]. PTH (1-84) is available in the U.S. at a once daily dosage of $50 \mu \mathrm{g}$ (Natpara ${ }^{\circledR}$, NPS Pharmaceuticals, Inc, Bedminster, NJ, USA) [26]. However, due to the occurrence of osteosarcomas and death in rat toxicology studies of rhPTH (1-34) [27], the FDA does not permit administration of $\mathrm{PTH}(1-34)$ to children or adults younger than 24 years of age, and PTH is not approved by the FDA for use in hypoparathyroidism [12,27]. PTH (1-84) was only recently approved in 2015 in the US for the treatment of osteoporosis and because of the potential risk of osteosarcoma, it is recommended only for patients who cannot be well-controlled on calcium supplements and active forms of vitamin $\mathrm{D}$ alone. The available preparations of PTH can only be used once daily, as twice daily administration will cause hypercalcemia in most patients $[26,28]$.

PTH-replacement therapy may work best using flexible dosing to adjust to the needs of different patients [13]. One study evaluated the efficacy and safety of PTH (1-34) in adults with hypoparathyroidism who received titrated PTH dosing aimed at normalizing calcium levels in the blood and urine [13]. In the study, the doses of the PTH (1-34) or calcitriol were adjusted to achieve serum calcium levels within the normal, or just below the normal, range [13]. The study found that, during a 3-year follow-up, serum calcium levels and urine calcium excretion were essentially within the normal range in the PTH (1-34) treated patients [20]. In contrast, only the serum calcium levels were within the normal range for the calcitriol treated patients. The bone mineral content and bone mineral density also improved to a greater extent with the PTH (1-34) compared with the calcitriol treatment [13]. In general, the findings were similar to the study of Winer et al. (2010) [16] that also used flexible dosing in children aged 5-14 years except there was no difference in the serum calcium levels between PTH (1-34) and calcitriol [16]. In contrast to PTH (1-34), studies with PTH (1-84) have only assessed fixed doses of PTH. Currently due to the fixed daily dosing of commercially available PTH-replacement therapy, the use of these drugs should be as an experimental treatment in patients in which calcium levels cannot be maintained using conventional methods [6]. Further, well designed studies that use similar dosing strategies are required to better understand the long-term efficacy and safety of treating hypoparathyroidism with PTH-replacement therapy.

All included studies were randomized trials ( 4 being RCTs and one being a randomized cross-over study). However, our metaanalysis has several limitations. The overall sample size was small, partly reflecting the rarity of this disease. The studies differed in populations ( 3 enrolled primarily female adults women, and 2 studies were performed in children) and active drug (2 studied PTH (1-84) and 3 investigated PTH (1-34). Although, the pharmacokinetics and pharmacodynamics may differ slightly between PTH (1-84) and PTH (1-34) [26,28], the published results do not indicate any apparent difference in efficacy between the 2 molecules $[6,23]$. However to date, there has not been a head-to-head study between PTH (1-84) and PTH (1-34) [6]. In addition, the studies with PTH (1-34) and PTH (1-84) differed in design and purpose; PTH (1-34) studies titrated doses of the molecule to normalize both urine and calcium levels, while studies with PTH (1-84) used a fixed dose along with calcitriol and calcium. Calcitriol, which was co-administered with PTH in 3 of the 5 included studies has potent calcemic and calciuric effects, which may confound the interpretation of the "true" PTH effect. Another limitation of our analysis is that it did not evaluate changes in symptoms resulting from PTH-replacement therapy. The follow-up time in the 3 of the 4 the studies, which enrolled adults, was $<6$ months $[13,14,21]$. The other study evaluated PTH (1-34) therapy up to 3 years in adults and found it was safe and effective [18]. Additional long-term studies are necessary to further determine the long-term effects of PTH therapy. This is important as treatment of hypoparathyroidism, a life-long disorder, requires long-term therapy [6]. Only one study investigated the twice daily administration of PTHreplacement therapy in children (5-14 years of age) [16]. They found that, up to 3-years, treatment with PTH (1-34) was well 
tolerated and was similar to calcitriol treatment in maintaining normal serum and urine calcium levels, kidney function, bone mineral accrual, and developmental growth. Similar to adults, longer term studies in children are required to establish the efficacy and safety of PTH-replacement in treating hypoparathyroidism in this young patient population. In addition, there is evidence that hyperparathyroidism may be associated with thyroid carcinomas in about $3 \%$ of patients [29]. It would be of interest to further investigate the relationship of hyperparathyroidism and the risk of thyroid cancer and the effect of PTH therapy on this risk.

\section{Conclusion}

\section{$\nabla$}

In conclusion, our meta-analysis suggests that, in patients with hypoparathyroidism, PTH (1-34), but no PTH (1-84) replacement therapy, can maintain the serum calcium levels in normal range by reducing the levels of urine calcium. However, serum phosphate level is reduced by PTH (1-84)-replacement therapy but not by PTH (1-34). Both PTH (1-34) and PTH (1-84)-replacement therapy may maintain the serum level of 1,25-dihydroxyvitamin D. It may be achieved by improving conversion of 25 -dihydroxyvitamin $\mathrm{D}$ by $1 \alpha$-hydroxylase to 1,25 -dihydroxyvitamin D, which results in a decrease in serum levels of 25-dihydroxyvitamin D.

\section{Acknowledgements}

$\nabla$

The authors thank Professor Yiming Li (Department of endocrinology, Huashan Hospital, Shanghai Medical College,Fudan University) and Professor Yu Wang(Department of Head and Neck Surgery, Cancer Hospital, Fudan University) for valuable conversations.

\section{Conflict of Interest}

The authors declare no conflict of interest.

\section{References}

1 Kim ES, Keating GM. Recombinant Human Parathyroid Hormone (1-84): A Review in Hypoparathyroidism. Drugs 2015; 75: 1293-1303

2 Rosato L, Avenia N, Bernante P, De Palma M, Gulino G, Nasi PG, Pelizzo $M R$, Pezzullo L. Complications of thyroid surgery: analysis of a multicentric study on 14,934 patients operated on in Italy over 5 years. World J Surg 2004; 28: 271-276

3 Youngwirth L, Benavidez J, Sippel R, Chen H. Parathyroid hormone deficiency after total thyroidectomy: incidence and time. J Surg Res 2010; 163: 69-71

4 Bergenfelz A, Jansson S, Martensson H, Reihner E, Wallin G, Kristoffersson A, Lausen I. Scandinavian Quality Register for Thyroid and Parathyroid Surgery: audit of surgery for primary hyperparathyroidism. Langenbecks Arch Surg 2007; 392: 445-451

5 Bilezikian JP, Khan A, Potts JT Jr, Brandi ML, Clarke BL, Shoback D, Juppner H, D'Amour P, Fox J, Rejnmark L, Mosekilde L, Rubin MR, Dempster D, Gafni R, Collins MT, Sliney J, Sanders J. Hypoparathyroidism in the adult: epidemiology, diagnosis, pathophysiology, target-organ involvement, treatment, and challenges for future research. J Bone Miner Res 2011; 26: 2317-2337

6 Rejnmark L, Sikjaer T, Underbjerg L, Mosekilde L. PTH replacement therapy of hypoparathyroidism. Osteoporos Int 2015; 24: 1529-1536

7 Pollak MR, Brown EM, Estep HL, McLaine PN, Kifor O, Park J, Hebert SC, Seidman CE, Seidman JG. Autosomal dominant hypocalcaemia caused by a $\mathrm{Ca}(2+)$-sensing receptor gene mutation. Nat Genet 1994; 8 : 303-307
8 Baron J, Winer KK, Yanovski JA, Cunningham AW, Laue L, Zimmerman $D$, Cutler GB Jr. Mutations in the $\mathrm{Ca}(2+)$-sensing receptor gene cause autosomal dominant and sporadic hypoparathyroidism. Hum Mol Genet 1996; 5: 601-606

9 Christensen SE, Nissen PH, Vestergaard P, Mosekilde L. Familial hypocalciuric hypercalcaemia: a review. Curr Opin Endocrinol Diabetes Obes 2011; 18: 359-370

10 Watanabe S, Fukumoto S, Chang H, Takeuchi Y, Hasegawa Y, Okazaki $R$, Chikatsu N, Fujita T. Association between activating mutations of calcium-sensing receptor and Bartter's syndrome. Lancet 2002; 360: 692-694

11 Shoback D. Clinical practice. Hypoparathyroidism. N Engl J Med 2008; 359: 391-403

12 Horwitz MJ, Stewart AF. Hypoparathyroidism: is it time for replacement therapy? J Clin Endocrinol Metab 2008; 93: 3307-3309

13 Mannstadt M, Clarke BL, Vokes T, Brandi ML, Ranganath L, Fraser WD, Lakatos P, Bajnok L, Garceau R, Mosekilde L, Lagast $H$, Shoback $D$, Bilezikian JP. Efficacy and safety of recombinant human parathyroid hormone (1-84) in hypoparathyroidism (REPLACE): a double-blind, placebo-controlled, randomised, phase 3 study. Lancet Diabetes Endocrinol 2013; 1: 275-283

14 Sikjaer T, Rejnmark L, Rolighed L, Heickendorff L, Mosekilde L, Hypoparathyroid Study G. The effect of adding $\mathrm{PTH}(1-84)$ to conventional treatment of hypoparathyroidism: a randomized, placebo-controlled study. J Bone Miner Res 2011; 26: 2358-2370

15 Mittendorf EA, Merlino JI, McHenry CR. Post-parathyroidectomy hypocalcemia: incidence, risk factors, and management. Am Surg 2004; 70 : 114-119

16 Winer KK, Sinaii N, Reynolds J, Peterson D, Dowdy K, Cutler GB Jr. Longterm treatment of 12 children with chronic hypoparathyroidism: a randomized trial comparing synthetic human parathyroid hormone 1-34 versus calcitriol and calcium. J Clin Endocrinol Metab 2010; 95: 2680-2688

17 Watanabe A, Yoneyama S, Nakajima M, Sato N, Takao-Kawabata $R$ Isogai Y, Sakurai-Tanikawa A, Higuchi K, Shimoi A, Yamatoya H, Yoshida $K$, Kohira T. Osteosarcoma in Sprague-Dawley rats after long-term treatment with teriparatide (human parathyroid hormone (1-34)). J Toxicol Sci 2012; 37: 617-629

18 Winer KK, Ko CW, Reynolds JC, Dowdy K, Keil M, Peterson D, Gerber LH, McGarvey C, Cutler GB Jr. Long-term treatment of hypoparathyroidism: a randomized controlled study comparing parathyroid hormone-(1-34) versus calcitriol and calcium. J Clin Endocrinol Metab 2003; 88: 4214-4220

19 Higgins JPT. Cochrane Collaboration Handbook for Systematic Reviews of Interventions Version 5.1.0 [updated March 2011]. The Cochrane Collaboration 2011 Available from www.cochrane-handbook.org 2011

20 Sutton AJ, Duval SJ, Tweedie RL, Abrams KR, Jones DR. Empirical assessment of effect of publication bias on meta-analyses. BMJ 2000; 320: 1574-1577

21 Winer KK, Yanovski JA, Cutler GB Jr. Synthetic human parathyroid hormone 1-34 vs calcitriol and calcium in the treatment of hypoparathyroidism. JAMA 1996; 276: 631-636

22 Winer KK, Yanovski JA, Sarani B, Cutler GB Jr. A randomized, cross-over trial of once-daily versus twice-daily parathyroid hormone 1-34 in treatment of hypoparathyroidism. J Clin Endocrinol Metab 1998; 83: 3480-3486

23 Cusano NE, Rubin MR, Sliney JJr, Bilezikian JP. Mini-review: new therapeutic options in hypoparathyroidism. Endocrine 2012; 41: 410-414

24 Vanhees I, Gunst J, Janssens T, Wauters A, Van Herck E, Van Cromphaut $S$, Van den Berghe G, Owen HC. Enhanced immunoreceptor tyrosinebased activation motif signaling is related to pathological bone resorption during critical illness. Horm Metab Res 2013; 45: 862-869

25 Rauchova H, Vokurkova M, Pavelka S, Behuliak M, Tribulova N, Soukup T. $\mathrm{N}-3$ polyunsaturated fatty acids supplementation does not affect changes of lipid metabolism induced in rats by altered thyroid status. Horm Metab Res 2013; 45: 507-512

26 PTH 1-84 (Natpara $\left.^{\circledR}\right)$ prescribing information NJ, USA

27 Tashjian AH Jr, Gagel RF. Teriparatide [human PTH(1-34)]: 2.5 years of experience on the use and safety of the drug for the treatment of osteoporosis. J Bone Miner Res 2006; 21: 354-365

28 Teriparatide (Forteo ${ }^{\circledR}$ ) prescribing information [cited 2014 September 4]. Available from http://pi.lilly.com/us/forteo-pi.pdf

29 Lehwald N, Cupisti K, Krausch M, Ahrazoglu M, Raffel A, Knoefel WT. Coincidence of primary hyperparathyroidism and nonmedullary thyroid carcinoma. Horm Metab Res 2013; 45: 660-663 